\title{
Assessment of enhanced biological phosphorus removal process inhibition
}

\author{
Kati Klein ${ }^{1}$ (D) Anni Mandel ${ }^{1} \cdot$ Hegne Lilleoja $^{1} \cdot$ Siim Salmar $^{1} \cdot$ Taavo Tenno $^{1}$
}

Received: 11 May 2020 / Accepted: 28 July 2020 / Published online: 10 August 2020

(c) Springer Nature Switzerland AG 2020

\begin{abstract}
Wastewater in industrial regions frequently contains substances which are potentially inhibitory to activated sludge treatment processes. Enhanced biological phosphorus removal (EBPR) is vulnerable to process inhibition mostly because of the location at the beginning of the treatment process and complex characteristics of influent. Much knowledge has been developed on the EBPR process; nonetheless, methods used for estimation of the process inhibition vary largely. There is no easily applicable and reliable method available for rapid determination of inhibition of the EBPR process. In this study, a method for evaluation of inhibition on the EBPR process was developed and controlled. In contrast with previous research, a fresh non-acclimated inoculum was used to enhance the possibility to predict the impact for wastewater treatment plant. The efficiency of the process was evaluated based on the values of orthophosphate release and uptake, synthesis and consumption of polyhydroxyalkanoates. 3,5-dichlorophenol (3,5-DCP) was used as a model inhibitory compound. It was found that the EBPR inhibition tests using a non-acclimated sludge need wastewater as the organic carbon source. Furthermore, the length of aerobic period substantially influenced the inhibition test resultsachieved maximum inhibitory concentration $\left(\mathrm{IC}_{50}\right)$ values were 2.4 times higher when aerobic phase was $6 \mathrm{~h}$ instead of $1.5 \mathrm{~h}$. Consequently, extended aeration period was suggested to diminish the inhibition effect. Finally, the impact of the 3,5-DCP on different activated sludge treatment process using respective standard methods was tested and compared. It was found that EBPR process was similarly to the nitrification a sensitive activated sludge process.
\end{abstract}

Keywords Activated sludge · Industrial wastewater · Inhibition test · Polyhydroxyalkanoates (PHA) · Polyphosphate accumulating organism (PAO)

\section{Introduction}

Anthropogenic release of phosphorus $(P)$ is an environmental risk since it is a key driver of eutrophication. On the other hand, demand for $\mathrm{P}$ as a fertilizer is globally increasing as its reserves are decreasing. In enhanced biological phosphorus removal (EBPR) process, $\mathrm{P}$ is removed from wastewater and accumulated to waste activated sludge (WAS) by polyphosphate accumulating microorganisms (PAOs). Efficiently treated P-enriched biomass can be further used as a fertilizer directly or indirectly. Thus, it is essential to achieve and maintain efficient biological phosphorus removal process in wastewater treatment plants (WWTPs).

Selectivity of PAOs is achieved by alternating anaerobic and aerobic conditions or application of the aerobic/ extended-idle (AEI) regime [1]. In conventional EBPR process, PAOs consume energy gained from hydrolysis of polyphosphate and glycogen degradation to take up volatile fatty acids (VFAs) under anaerobic conditions, which are converted to polyhydroxyalkanoates (PHAs). Ortho-phosphates are released from bacterial cells during degradation of poly-phosphates, and the concentration of orthophosphates increases in liquid phase. PHAs

Kati Klein, kati.klein@ut.ee | Institute of Chemistry, University of Tartu, 14a Ravila St., 50411 Tartu, Estonia. 
are biopolyesters synthesized by bacteria as intracellular storage reserves of carbon and energy. PHA polymers commonly stored by PAOs are poly- $\beta$-hydroxybutyrate (PHB), polyhydroxyvalerate (PHV) and poly- $\beta$-hydroxy-2methylvalerate $\left(\mathrm{PH}_{2} \mathrm{MV}\right)$ [2].

The exact type of produced polymer depends on the composition of VFAs in the wastewater and inoculum. When the most abundant VFA is acetate, then mostly PHB is stored, $\mathrm{PHV}$ and $\mathrm{PH}_{2} \mathrm{MV}$ are stored when propionate is the abundant VFA [3]. Furthermore, when glycogenaccumulating organisms (GAOs) are present in inoculum, the sludge stores higher amounts of PHV [4]. In following aerobic conditions, PHAs are respired to provide energy for cell metabolism and accumulate excessive poly-P to microbial cells.

The biological phosphorus removal process is the first step in an EBPR wastewater treatment plant, where the concentration of organic compounds as well as other pollutants and potential inhibitors is the highest when compared to other wastewater treatment processes. PAOs are vulnerable to hazardous substances and prone to the process inhibition because of the location of the EBPR process and complex composition of sewage containing potential inhibitors. There are several substances in wastewater which inhibit biological phosphorus removal processpharmaceuticals (doxycycline, tetracycline, diclofenac), heavy metals (copper, tin, silver, chromium), salts, $\mathrm{H}_{2} \mathrm{~S}$ and nanomaterials [5-12].

Today, several methods are used to estimate the impact of wastewater or hazardous substance on activated sludge processes: ISO 8192 for assessing the inhibition of oxygen consumption by activated sludge, ISO 9509 for assessing the inhibition on nitrification of activated sludge microorganisms and ISO 9888 for evaluating the aerobic biodegradability of organic compounds [13-15]. Application of inhibition tests enables to choose the treatment technology [16]. Furthermore, inhibition tests are tools to reduce flows of hazardous substances to WWTPs and thereby increase the treatment efficiency and the quality of WAS. Nevertheless, there is no reliable and easily applicable method for estimating the inhibition of EBPR process. There are several studies showing the impact of hazardous compounds on biological phosphorus removal process, but used methods require setup and operation of laboratory reactor for pre-adaption of the inoculum until steady-state conditions are achieved [5, 8, 9]. Furthermore, it has been discussed that inhibition results depend on the difference of applied operating conditions of acclimatization system, such as temperature and organic carbon type. Different acclimatization procedures may affect the physical characteristics and microbial composition of the acclimated sludge [17]. More advanced techniques for estimating the efficiency and potential inhibition of biological phosphorus removal process are based on the fluorescence in situ hybridization (FISH) and Raman-FISH $[5,18]$.

The aim of this study was to develop and test feasible and reliable method for evaluation of the activated sludge biological phosphorus removal process. The method gives a possibility to estimate the inhibition of wastewater or hazardous substances on PAOs and to identify the origin of wastewater inhibiting the process without setup of the acclimatization reactor.

\section{Materials and methods}

\subsection{Analytical methods}

Standard methods for examination of water and wastewater [19] were used in order to determine the chemical oxygen demand (COD), $\mathrm{PO}_{4}-\mathrm{P}$ and $\mathrm{MLSS}$. $\mathrm{pH}$ was measured with an $\mathrm{E} 6115 \mathrm{pH}$ meter (Evikon, Estonia) and concentration of dissolved oxygen with Marvet Junior 2000 portative oxygen analyzer (Elke Sensor, Estonia). $\mathrm{NO}_{3}-\mathrm{N}$ and $\mathrm{NO}_{2}-\mathrm{N}$ were determined by spectrophotometric methods according to SFS 5752 and SFS 3029, respectively. Dissolved organic carbon (DOC) was measured with Analytik Jena Multi N/C 3000 TOC analyzer. The concentration of acetate was measured using an ion chromatograph Metrohm 930 Compact IC Flex equipped with a column Metrosep A Supp 5 100/0.4 (Metrohm, Switzerland). $\mathrm{NH}_{4}{ }^{+} \mathrm{N}$ was determined using the $\mathrm{HACH}$-Lange spectrophotometric method with Nessler reagent (ISO 7150-1). The results of all the analyses were expressed as the mean with standard deviations of at least 3 parallel replicates.

\subsection{Analysis of PHAs}

PHAs were analyzed by the method proposed by Oehmen et al. [20]. All microbial samples were centrifuged and immediately frozen at $-20^{\circ} \mathrm{C}$ until final measurements. Frozen samples were lyophilized during $20 \mathrm{~h}$ in a Christ Alpha 1-2 freeze dryer operated at $-49{ }^{\circ} \mathrm{C}$ and $0.7 \mathrm{mbar}$ connected with a Vacuubrand RZ 2.5 vacuum pump. Lyophilized biomass was weighted into a glass tube, where $2 \mathrm{~mL}$ of acidic methanol $\left(10 \% \mathrm{H}_{2} \mathrm{SO}_{4} \mathrm{v} / \mathrm{v}\right)$ and $2 \mathrm{~mL}$ of chloroform were added. The tubes were sealed and incubated at $105^{\circ} \mathrm{C}$ for $2 \mathrm{~h}$ for derivatization and subsequently cooled. $2 \mathrm{~mL}$ of derivatized sample was mixed with $1 \mathrm{~mL}$ of milliQ water applying a vortex to facilitate the separation of two phases. The chloroform phase was extracted and traces of water were removed with $\mathrm{Na}_{2} \mathrm{SO}_{4}$. The sample was extracted into a CG vial and analyzed immediately.

$2 \mu \mathrm{L}$ of sample was injected in an Agilent Technologies 7890A gas chromatograph equipped with 5975C inert MSD system with Triple-Axis Detector, G4513A 
Autosampler and HP-5MS column ( $30 \mathrm{~m}, 0.25 \mathrm{~mm}$ internal diameter, $0.25 \mu \mathrm{m}$ film thickness, Agilent Technologies). Helium was used as a carrier gas. A co-polymer of poly(3hydroxybutyric acid-co-3-hydroxyvaleric acid), natural origin, 88:12 wt, Aldrich was used as a standard. Standards were processed in the same way as the samples, after being dissolved into a chloroform solution.

Production of PHAs was calculated as concentration difference between start point and end of anaerobic period. PHA consumption was calculated as concentration difference between the end of anaerobic period and the end of aerobic period. Inhibition of PHA production/consumption was calculated as following:

$I_{\mathrm{PHA}}=\frac{\left(C_{0}-C_{x}\right)}{C_{0}} \times 100 \%$

$I_{\mathrm{PHA}}$-inhibition of $\mathrm{PHB}$ or PHV production/consumption, $\%, C_{0}$ - concentration of PHB or PHV at the end of anaerobic cycle, $\mathrm{mg} \mathrm{mg}^{-1}, C_{x}$-concentration of PHB or PHV at start point (PHA production) or at the end of aerobic cycle (PHA consumption), $\mathrm{mg} \mathrm{mg}^{-1}$.

\subsection{Setup of activated sludge batch experiments}

Activated sludge used in this study was taken from municipal WWTP (100 000 PE) with efficient biological phosphorus removal process coupled with chemical P-removal and final filtration to achieve effluent total phosphorus concentration below $0.5 \mathrm{mg} \mathrm{L}^{-1}$, sludge retention time (SRT) in the WWTP was 30 days, and average activated sludge concentration in biological treatment was $7 \mathrm{~g} \mathrm{~L}^{-1}$. A returned sludge was used to avoid preceding accumulation of polyhydroxyalkanoates in the microbial cells. Activated sludge was continuously aerated until the test at ambient temperature. Batch experiments were conducted with activated sludge sampled in less than $24 \mathrm{~h}$. Activated sludge was previously washed by applying centrifugation at 1000 RMP for 2 min in $250 \mathrm{~mL}$ tubes to prevent any influence from wastewater.

Experiments were performed in $1000 \mathrm{~mL}$ Pyrex bottles, which contained $100 \mathrm{~mL}$ of $2 \mathrm{~g} \mathrm{~L}^{-1}$ sodium-acetate solution, $1 \mathrm{~mL}$ phosphate buffer, $1 \mathrm{~mL} \mathrm{MgSO}{ }_{4} \times 7 \mathrm{H}_{2} \mathrm{O}$, $1 \mathrm{~mL} \mathrm{CaCl} 2 \times 7 \mathrm{H}_{2} \mathrm{O}, 1 \mathrm{~mL} \mathrm{FeCl}{ }_{3} \times 6 \mathrm{H}_{2} \mathrm{O}, 2 \mathrm{~mL}$ acidic microelements, $2 \mathrm{~mL}$ basic microelements, $550 \mathrm{~mL}$ municipal wastewater (if not stated otherwise), a toxicant (3,5-dichlorophenol) and $300 \mathrm{~mL}$ of activated sludge mixture. Concentration of added activated sludge mixture should be calculated based on targeted MLSS value in the test bottle. In this study, MLSS value in the test was $4 \pm 0.8 \mathrm{~g} \mathrm{~L}^{-1}$ and respective value of the added activated sludge mixture was $13 \mathrm{~g} \mathrm{~L}^{-1}$ on average. Two parallel bottles of blank control without inhibitor were used in each test. Municipal wastewater used in the tests was taken from the same WWTP. Recipes of acidic and basic microelements were taken from Zhang et al. [21]. $\mathrm{K}_{2} \mathrm{HPO}_{4}$ was added in order to avoid phosphorus limitation for the EBPR process. $\mathrm{NaHCO}_{3}$ should be added when used wastewater has a low alkalinity. Wastewater and sludge were both at ambient temperature to avoid temperature shock. Experiment consisted of $1 \mathrm{~h}$ anaerobic followed by $6 \mathrm{~h}$ of aerobic phase.

First, samples (starting point) were collected and centrifuged immediately after addition of inoculum. Bottles containing inoculum, wastewater, microelements and toxicant were purged with $\mathrm{N}_{2}$ to avoid oxygen intrusion and aerated with compressed air during anaerobic and aerobic phases, respectively. Concentration of dissolved oxygen and value of $\mathrm{pH}$ were monitored during the whole experiment. $\mathrm{pH}$ was regulated with a $4 \mathrm{M} \mathrm{HCl}$ solution (if necessary) to be below 8 . Samples were taken after 1.5, $2.5,4$ and $6 \mathrm{~h}$ under aerobic conditions $(30 \mathrm{~mL}$ for analysis of PHAs and $20 \mathrm{~mL}$ for other parameters). Continuous stirring was applied during the experiment. All samples were taken from fully-mixed conditions to ensure that sampling would not change the MLSS value of the test. Supernatant was decanted and solid phase was put into a drying oven $\left(105^{\circ} \mathrm{C}\right)$ right after centrifugation (4750 RPM, $10 \mathrm{~min}$ ) to avoid potential phosphorus back-leaching or any other changes of the samples. $\mathrm{PO}_{4}-\mathrm{P}, \mathrm{COD}$ were analyzed from liquid phase and $\mathrm{PO}_{4}-\mathrm{P}, \mathrm{PHAs}$ from solid phase. Concentrations of DOC and acetate were measured from the liquid phase to ensure sufficiency of VFAs. Experiments were performed at ambient temperature.

Inhibition tests were done in seven parallel replicates during the control of the developed method; in three parallel replicates when synthetic wastewater was used as a carbon source and in three parallel replicates when inhibition on activated sludge nitrification, denitrification and oxygen consumption were tested.

The percent of EBPR inhibition was calculated as following:

$R_{\mathrm{p}}=\frac{\left(C_{1}-C_{x}\right)}{\mathrm{MLSS}} \times \Delta t$

$I_{p}=\frac{\left(R_{\mathrm{p}, 0}-R_{\mathrm{p}, x}\right)}{R_{\mathrm{p}, 0}} \times 100 \%$

$R_{\mathrm{p}}$ - phosphorous release/uptake rate, $\mathrm{mgPO}_{4}-\mathrm{P} \mathrm{g}^{-1} \mathrm{MLSS}$ $\mathrm{h}^{-1}, \mathrm{C}_{1}$-concentration of $\mathrm{PO}_{4}-\mathrm{P}$ at the end of anaerobic cycle, $\mathrm{mg} \mathrm{L}^{-1}, \mathrm{C}_{x}$-total concentration of $\mathrm{PO}_{4}^{-\mathrm{P}}$ at the beginning of anaerobic cycle/chosen point of aerobic cycle, $\mathrm{mg} \mathrm{L}^{-1}$, MLSS - concentration of mixed liquid suspended solids, $\mathrm{g} \mathrm{L}^{-1}, \Delta t$-duration of chosen period, $\mathrm{h}$, $I_{\mathrm{p}}$-inhibition of phosphorous release/uptake process, $\%, R_{\mathrm{p}, 0}$ - phosphorous release/uptake rate in the control 
Table $1 \quad I_{50}$ values for 3,5-dichlorophenol for activated sludge oxygen consumption, nitrification and denitrification process

\begin{tabular}{llc}
\hline & $\mathrm{IC}_{50}$ from standard* $\left(\mathrm{mg} \mathrm{L}^{-1}\right)$ & Tested IC $\left.\mathrm{Img} \mathrm{L}^{-1}\right)$ \\
\hline $\begin{array}{l}\text { Oxygen consumption } \\
\text { (ISO 8192) }\end{array}$ & $9.3 \pm 3.7$ & $7.2 \pm 2.4$ \\
$\begin{array}{l}\text { Nitrification } \\
\text { (ISO 9509) }\end{array}$ & $5.6 \pm 3.0$ & $2.9 \pm 0.7$ \\
$\begin{array}{l}\text { Denitrification } \\
{[25]}\end{array}$ & No standard available & $5.5 \pm 2.2$ \\
\hline
\end{tabular}

*The mean concentration of the 3,5-DCP which reduces process rate by $50 \%$ accordingly to ISO 8292 and ISO 9509 standards vessel, $\mathrm{mgPO}_{4}-\mathrm{P} \mathrm{g}^{-1} \mathrm{MLSS}^{-1}$, and $R_{\mathrm{p}, x}$-phosphorous release/uptake rate in the test vessel at chosen inhibitor concentration, $\mathrm{mgPO}_{4}-\mathrm{P} \mathrm{g}^{-1} \mathrm{MLSS} \mathrm{h}^{-1}$.

\subsection{Characteristics of the model toxicant}

Tests were performed with a 3,5-dichlorophenol (3,5-DCP) solution $\left(1 \mathrm{~g} \mathrm{~L}^{-1}\right)$. The 3,5 -DCP has been used as a reference compound in ISO 9509 (toxicity test for assessing the inhibition of nitrification of activated sludge microorganisms), ISO 8192 (test for inhibition of oxygen consumption by activated sludge) and for toxicity test for assessing the inhibition of denitrification of activated sludge microorganisms by Klein and Tenno [25] (Table 1).

\section{Results and discussion}

\subsection{Selection of the carbon source for non-acclimated inoculum}

Synthetic wastewater containing acetate, propionate or lactate is mainly used as a sole carbon source in laboratory-scale EBPR studies. Furthermore, inoculum used in these studies has been previously acclimated in a laboratory-scale system until pseudo steady-state conditions $[8,9,17,22,23]$. Acclimatization of these systems takes usually 1.5-18 months. However, it is not feasible to setup a laboratory-scale acclimatization system for estimation the impact of wastewater or hazardous substance on activated sludge from different WWTPs because of the time expenditure, changed physical characteristics and microbial composition of acclimatized sludge. Thus, in this study biological phosphorus release and uptake tests were performed with a non-acclimated sludge from municipal WWTP and synthetic wastewater (acetate) as a carbon source (Fig. 1). Mean orthophosphate release and uptake rates for synthetic wastewater were $2.5 \mathrm{mgPO}_{4}-\mathrm{P} \mathrm{g}^{-1} \mathrm{MLSS}$ $\mathrm{h}^{-1}$ and $1.1 \mathrm{mgPO}_{4}-\mathrm{P} \mathrm{g}^{-1} \mathrm{MLSS} \mathrm{h}^{-1}$, respectively. Furthermore, the concentration of $\mathrm{PO}_{4}-\mathrm{P}$ was always higher in the effluent than in the influent. Additionally, an increase in the MLSS value up to $5.2 \mathrm{mg} \mathrm{L}^{-1}$ and applying preceding 1-cycle sludge acclimatization did not influence the result. Therefore, an EBPR batch test using synthetic wastewater and non-acclimated sludge cannot be used for estimation
Fig. 1 Phosphorus release and uptake profiles for EBPR batch tests with synthetic and municipal wastewater as a carbon source (I-anaerobic phase, II-aerobic phase). Error bars show the standard deviation of parallel tests (municipal wastewater: $n=7$, synthetic wastewater: $n=3$ )

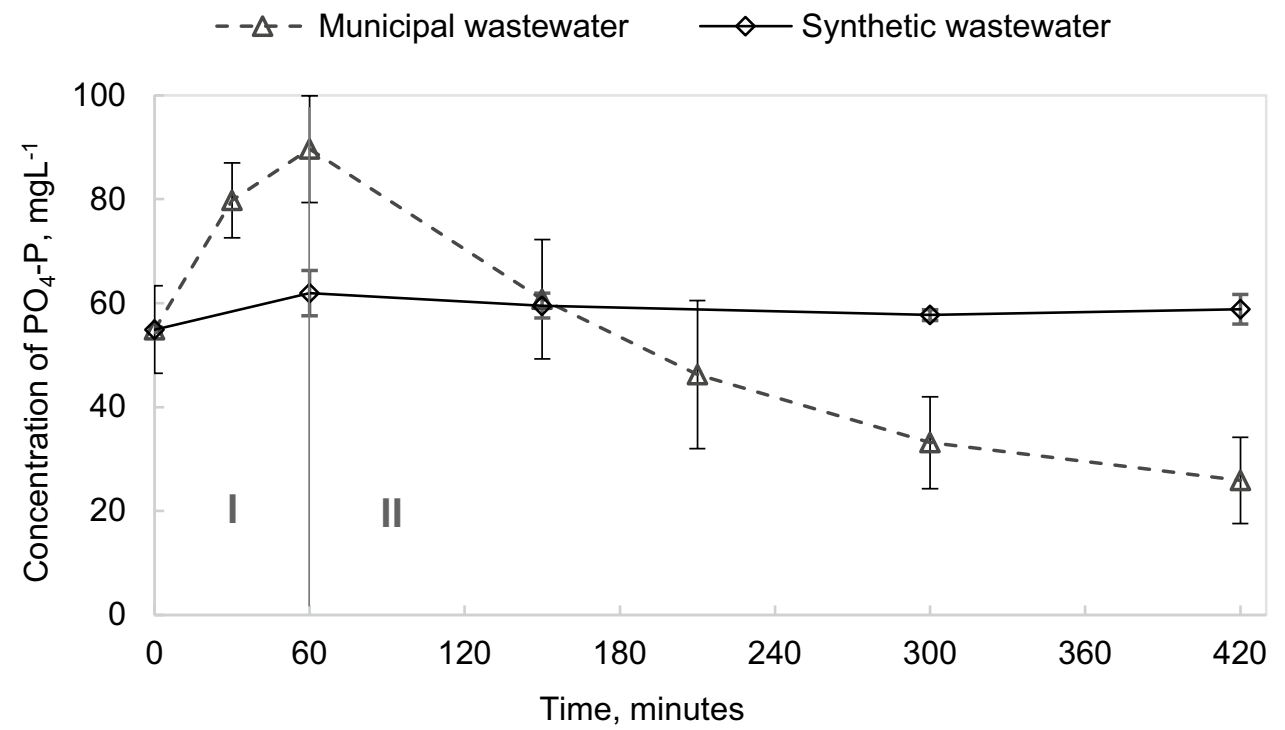


of the potential inhibition of any hazardous substance or wastewater on EBPR process.

Since various studies show that metabolism of PAOs substantially depends on the carbon source, influent of the same WWTP was used (Fig. 1). Results showed efficient P-release and -uptake activity-mean release during 1-h period was $8.7 \mathrm{mgPO}_{4}-\mathrm{P} \mathrm{g}^{-1} \mathrm{MLSS} \mathrm{h}^{-1}$ and mean uptake during $6 \mathrm{~h}$ of aeration was $15.9 \mathrm{mgPO}_{4}-\mathrm{P} \mathrm{g}^{-1} \mathrm{MLSS}^{-1}(2.65$ $\mathrm{mgPO}_{4}-\mathrm{P} \mathrm{g}^{-1} \mathrm{MLSS} \mathrm{h}^{-1}$ ). Approximate orthophosphate release and uptake rates for acclimatized sludge are reported $5 \mathrm{mgP} \mathrm{g}^{-1} \mathrm{VSS} \mathrm{h}^{-1}$ and $2 \mathrm{mgPg}^{-1} \mathrm{VSS} \mathrm{h}^{-1}$, respectively [6]. Municipal wastewater contains different VFAs, micro- and macro-elements required for the cell metabolism. Furthermore, better results from the batch tests with municipal influent could be achieved because versatility of the carbon sources in wastewater allows other PAOs to proliferate in coexistence or competition with $\mathrm{Ca}$. Accumulibacter [24]. It should be noted that presence of nitrite or nitrate in samples has to be excluded because electron acceptors (oxygen, nitrate or nitrite) inhibit anaerobic metabolism of PAOs.
However, since biological phosphorus release and uptake are significantly influenced by the composition of wastewater, variation of sludge and wastewater from two different municipal WWTPs with efficient EBPR processes was tested (Table 2). Results show that using influent from different municipal WWTPs does not significantly change the values of phosphorus release, uptake and removal. Using activated sludge or wastewater as a carbon source from another municipal WWTP is important when activity of PAOs has substantially decreased or estimation of inhibitory characteristics of the influent wastewater is required.

\subsection{Effect of 3,5-diclorophenol on anaerobic metabolism of polyphosphate accumulating organisms}

The method for estimating the impact of inhibitory substance on PAOs was tested by using 3,5-DCP as a model inhibitor. The 3,5-DCP is a reference compound that has been used for validation of tests for oxygen consumption

Table 2 Phosphate release, uptake and removal rates calculated from 0 to $60 \mathrm{~min}$ anaerobic and $6 \mathrm{~h}$ of aerobic conditions when sludge and wastewater (WW) from two different municipal WWTPs were used $(n=3)$

\begin{tabular}{llllll}
\hline Parameter & Unit & Inoculum A+WW A & Inoculum A+WW B & Inoculum B+WW B & $\begin{array}{l}\text { Inoculum } \\
\text { B +WW A }\end{array}$ \\
\hline Release & $\mathrm{mgPO}_{4}-\mathrm{P} \mathrm{g}^{-1} \mathrm{MLSS} \mathrm{h}^{-1}$ & 8.7 & 6.8 & 7.4 & 6.4 \\
Uptake & $\mathrm{mgPO}_{4}-\mathrm{P} \mathrm{g}^{-1} \mathrm{MLSS} \mathrm{h}^{-1}$ & 2.7 & 2.7 & 2.4 & 2.3 \\
Removal & $\mathrm{mgPO}_{4}-\mathrm{P} \mathrm{g}^{-1} \mathrm{MLSS} \mathrm{h}^{-1}$ & 1.2 & 1.6 & 1.2 & 1.3 \\
\hline
\end{tabular}

Fig. 2 Anaerobic orthophosphate release rates calculated from 30 and 60 min under 3,5-dichlorophenol concentrations from 0 to $10 \mathrm{mg} \mathrm{L}^{-1}$. Error bars show the standard deviation of parallel tests $(n=7)$

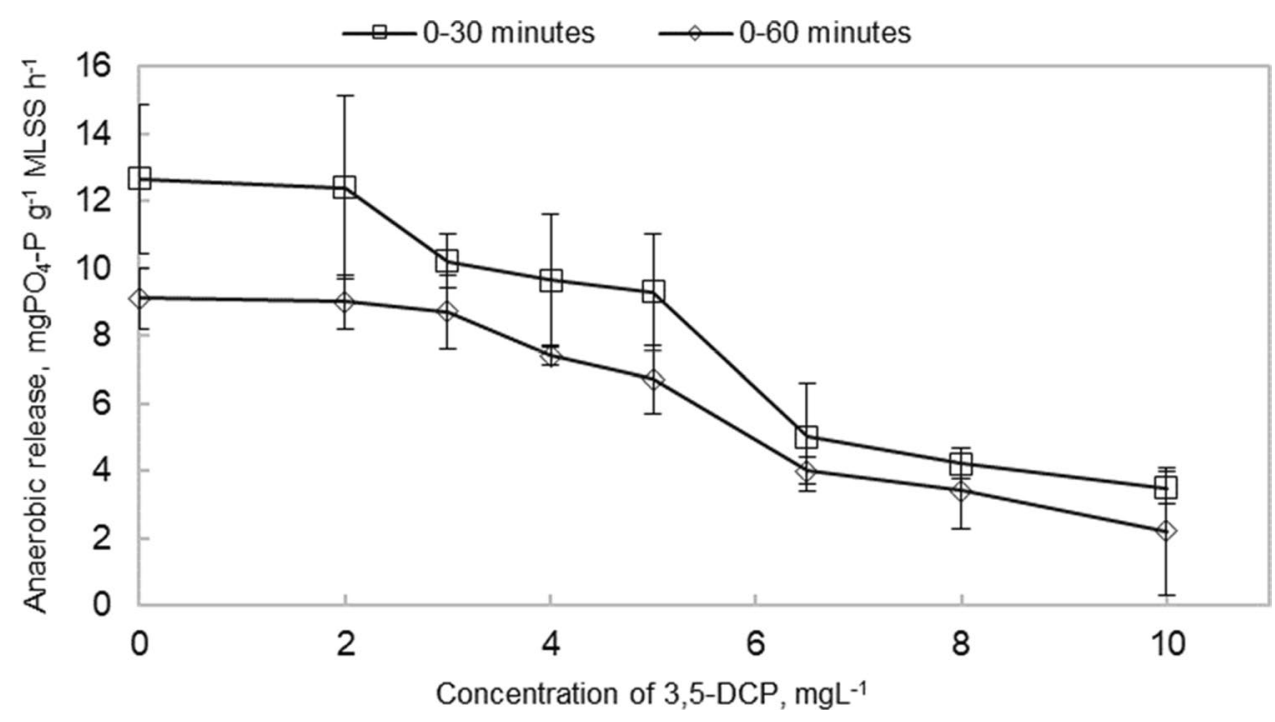

SN Applied Sciences 
by activated sludge (ISO 8192), toxicity test for assessing the inhibition of nitrification of activated sludge microorganisms (ISO 9509) and for estimating the impact of inhibitory substances on activated sludge denitrification process [25]. It is a persistent and highly toxic compound formed via dehalogenation of polychlorophenols [26].

It should be considered that precipitation of calcium phosphate is favored at $\mathrm{pH}$ value of 8 , and thereby, the initial phosphorus release rate seems to be more relevant as precipitation is of minor importance at the beginning of the release period where the phosphorus concentration is low [27]. Thus, calculation of release rates from the first $30 \mathrm{~min}$ of the anaerobic period to avoid the calcium phosphate precipitation effect when wastewater with higher alkalinity is used without $\mathrm{pH}$ control should be considered.

Although the $\mathrm{pH}$ value was controlled to be below 8 , phosphate release values were calculated from the first 30 and 60 min of anaerobic period to control the potential presence of the calcium phosphate precipitation at the end of the anaerobic period. On average, $25.7 \mathrm{mg} \mathrm{L}^{1}$ of phosphate was released during 60 min of anaerobic conditions, from which $17 \mathrm{mg} \mathrm{L}^{1}(66 \%)$ was released during first $30 \mathrm{~min}$ and remaining $8.7 \mathrm{mg} \mathrm{L}^{1}(34 \%)$ in following $30 \mathrm{~min}$. Additionally, shapes of process rate curves shown on Fig. 2 for 30 and 60 min of test period are similar. On average, $66 \%$ of phosphate was released during the first 30 min of anaerobic conditions which causes higher value of the release rate. Average orthophosphate release rate in $30 \mathrm{~min}$ was $12.6 \mathrm{mgPO}_{4}-\mathrm{Pg}^{-1} \mathrm{MLSS} \mathrm{h}^{-1}$ and $9.1 \mathrm{mgPO}_{4}-\mathrm{P}$ $\mathrm{g}^{-1} \mathrm{MLSS} \mathrm{h}^{-1}$ in $60 \mathrm{~min}$. However, the phosphate release at lower concentrations of inhibitor (up to $3 \mathrm{mg} \mathrm{L}^{-1}$ ) was slightly lower during the first $30 \mathrm{~min}$ and caused $15 \%$ higher inhibition value. Thus, the release rates used in this study are calculated from the $60 \mathrm{~min}$ of the anaerobic period to avoid overestimation of the inhibition.

Figures 2 and 3 show that 3,5-DCP substantially reduces the anaerobic orthophosphate release and PHA synthesis. Anaerobic PHA synthesis considerably decreased with increase in inhibitor concentration-63.8\% less PHB and $50.6 \%$ less PHV were synthesized under inhibitor concentration of $10 \mathrm{mg} \mathrm{L}^{-1}$. Inhibitor may cause severe damage to the cell membrane and destroy enzymes. It reduces poly$P$ degradation, leading to insufficient adenosine triphosphate (ATP) required for the synthesis of PHAs $[8,28]$. Thus, inhibition of the orthophosphate release causes inhibition of the EBPR process.

It revealed that $6.2 \mathrm{mg} \mathrm{L}^{-1}$ of $3,5-\mathrm{DCP}$ inhibits $50 \%$ of anaerobic phosphorus release rate and although 3,5-DCP substantially reduced anaerobic orthophosphate release, complete inhibition did not occur under the 3,5-DCP concentration up to $10 \mathrm{mg} \mathrm{L}^{-1}$ (Fig. 6). It would be beneficial to monitor the anaerobic process with phosphate sensor to identify the reduction in orthophosphate release and thereby identify potential inhibition of the process.

\subsection{Effect of 3,5-diclorophenol on aerobic metabolism of polyphosphate accumulating organisms}

Under aerobic conditions, degradation of PHAs leads to the generation of acetyl-CoA and propionyl-CoA, both of which enter TCA cycle as carbon and energy source for biomass growth, phosphate uptake and poly-P generation [29]. Thus, efficiency of aerobic metabolism of PAOs was
Fig. 3 Effect of 3,5-dichlorophenol (3,5-DCP) on anaerobic synthesis and aerobic consumption of poly- $\beta$ hydroxybutyrate (PHB) and polyhydroxyvalerate (PHV). Error bars show the standard deviation of parallel tests taken using sludge sampled during different seasons $(n=3)$

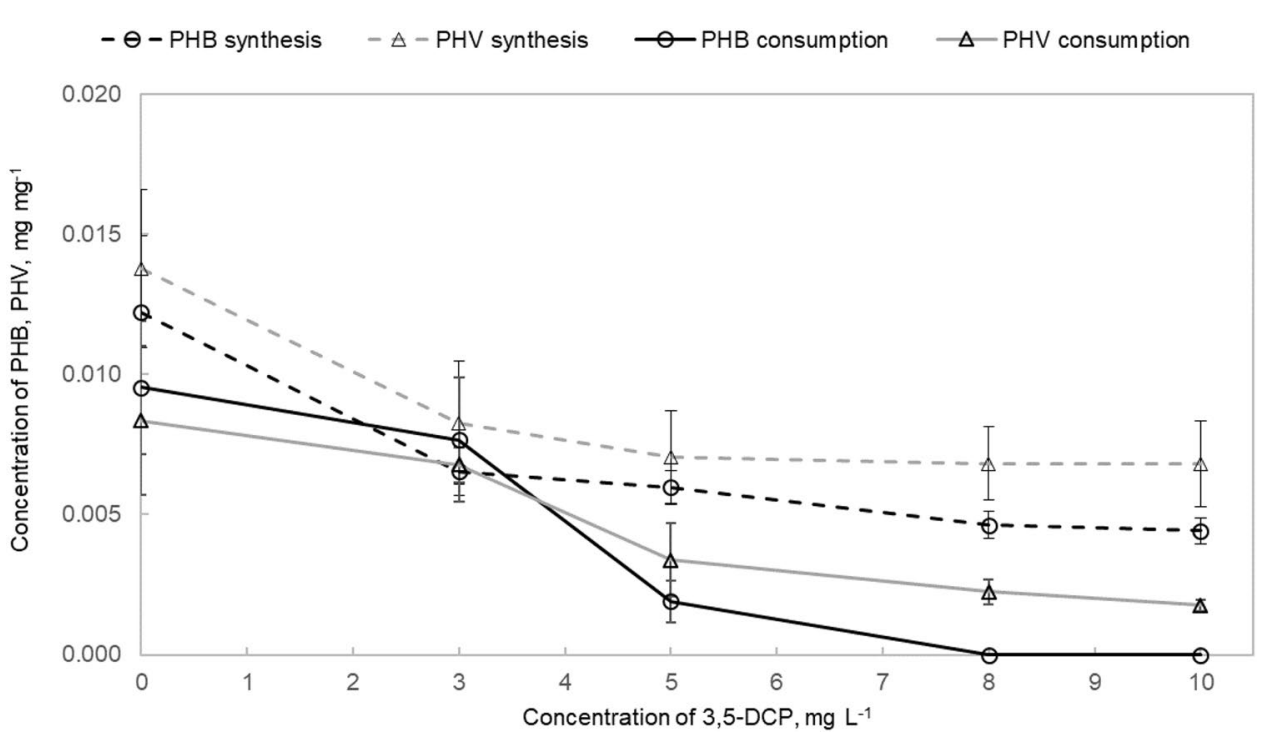


Fig. 4 Aerobic dynamics of soluble phosphate $\left(\mathrm{PO}_{4}-\mathrm{P}\right)$ during $6 \mathrm{~h}$ of aeration under 3,5-diclorophenol. Error bars show the standard deviation of parallel tests $(n=7)$

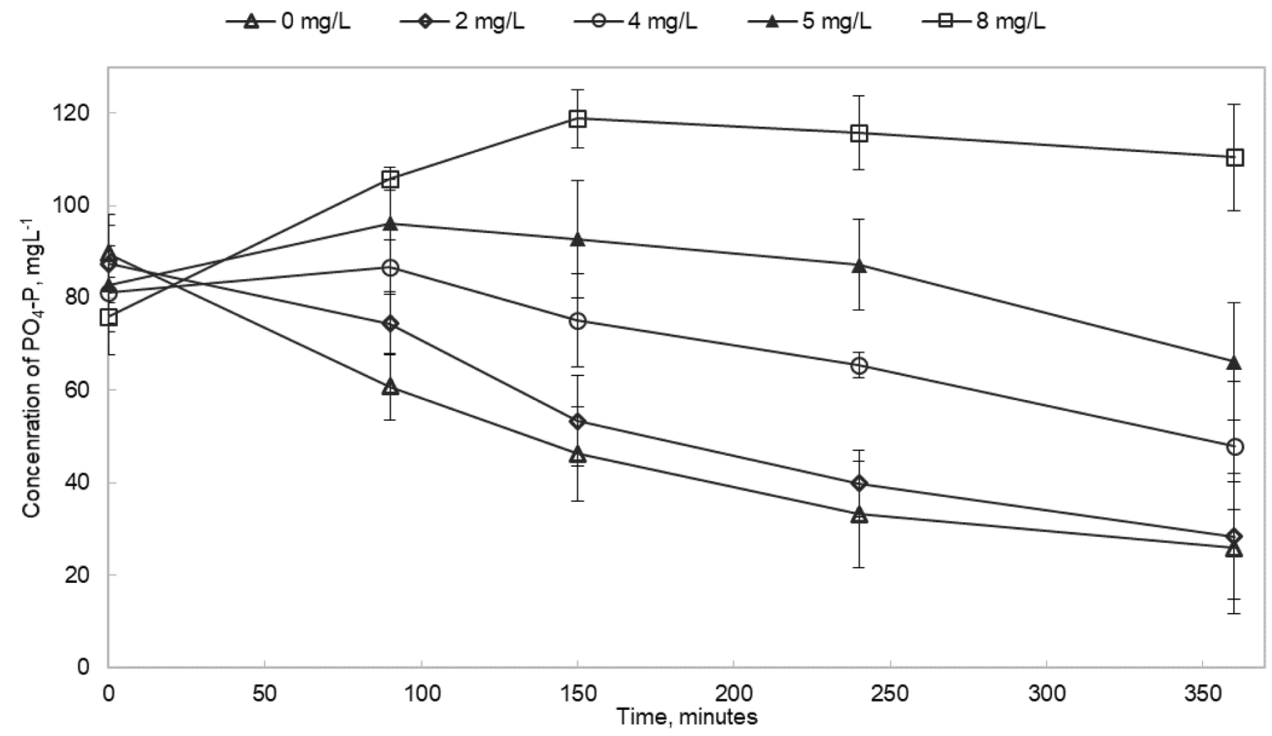

Fig. 5 Inhibition curves of aerobic phosphorus uptake under 3,5-dichlorophenol concentrations from 0 to $10 \mathrm{mg} \mathrm{L}^{-1}$ when phosphorus uptake rates were calculated from 0 to $90 \mathrm{~min}, 0$ to $150 \mathrm{~min}, 0$ to $240 \mathrm{~min}$ and 0 to 360 min of aeration $(n=7)$ $\smile 90 \mathrm{~min} \neg-150 \mathrm{~min} \backsim 240 \mathrm{~min} \quad \smile 360 \mathrm{~min}$

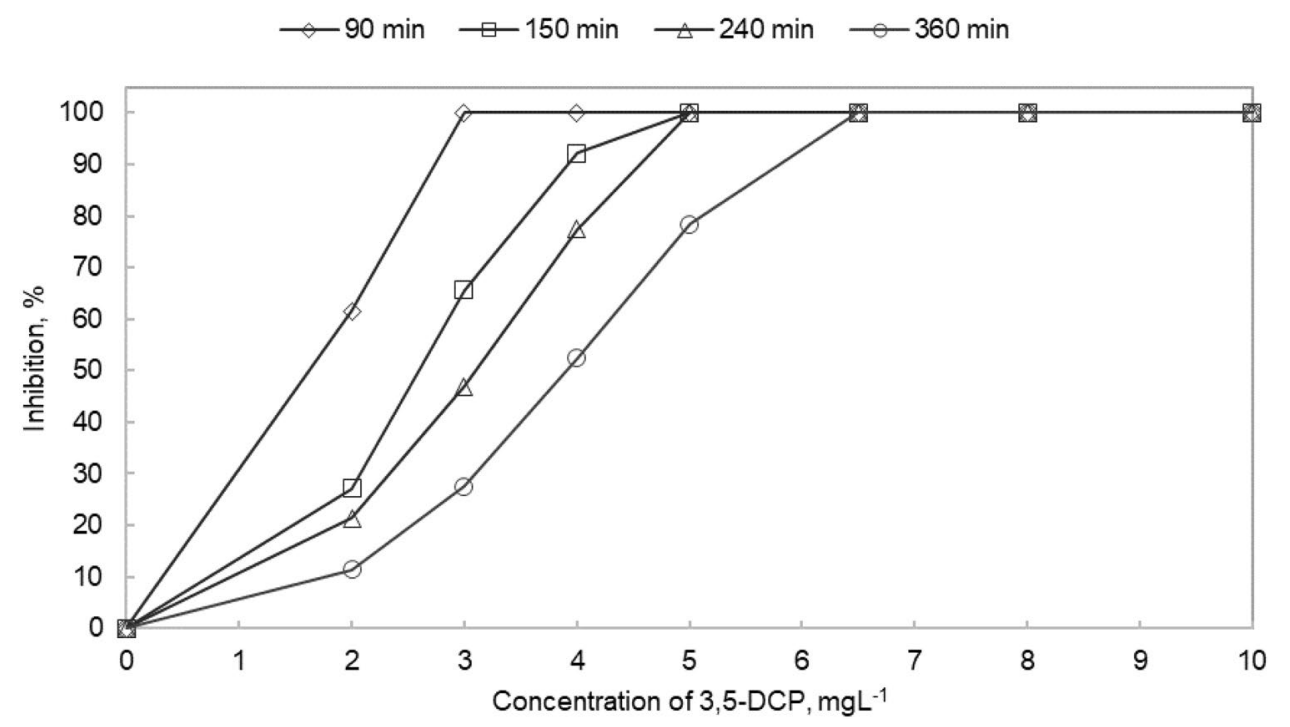

evaluated based on phosphate uptake and PHA consumption rates during $6 \mathrm{~h}$ of continuous aeration.

Figure 4 shows aerobic dynamics of soluble phosphate during aeration phase under 3,5-DCP concentrations from 0 to $8 \mathrm{mg} \mathrm{L}^{-1}$. Lower concentrations of inhibitor (up to 4 $\mathrm{mg} \mathrm{L}^{-1}$ ) reduces the phosphate uptake at the beginning of the aeration phase; however, phosphate release continues during aeration phase from 3,5-DCP concentration of $5 \mathrm{mg} \mathrm{L}^{-1}$. Subsequent phosphorus uptake in inhibited samples could be caused by decomposition of organic toxicant under aerobic conditions. Biological degradation of phenols has been previously reported by several authors $[26,30]$. Furthermore, starting from the inhibitor concentration of $5 \mathrm{mg} \mathrm{L}^{-1}$, concentration of phosphate was higher after $6 \mathrm{~h}$ on aeration than at beginning of the test. Additionally, Fig. 3 clearly shows that PHAs degradation rate decreased with increase in inhibitor concentration. 50\% of $\mathrm{PHB}$ and $\mathrm{PHV}$ degradation rates were inhibited under $3,5-\mathrm{DCP}$ concentrations of $4.0 \mathrm{mg} \mathrm{L}^{-1}$ and $4.5 \mathrm{mg} \mathrm{L}^{-1}$, respectively. $100 \%$ of $\mathrm{PHB}$ and $79 \%$ of PHV consumptions were inhibited under 3,5-DCP concentration of $10 \mathrm{mg} \mathrm{L}^{-1}$. Although it has been reported that PAOs have ability to take up substrate for synthesis of PHAs and growth of microorganisms under aerobic conditions in response to toxicity [6], no PHA synthesis was occurred when 3,5-DCP was used as an inhibitor. Compared with inhibition under anaerobic phase, 3,5-DCP had significantly higher inhibitory effect under aerobic conditions because inhibition of phosphorous uptake is clearly influenced by efficiencies of anaerobic polyphosphate degradation, PHA synthesis and aerobic PHA degradation processes. Higher sensitivity 
of aerobic process compared to anaerobic process is also reported in previous studies $[8,17]$.

Selection of suitable time for the aerobic phase for inhibition calculations is a relevant aspect of the test. Figure 5 shows differences in inhibition curves when calculations were made after 1.5, 2.5, 4 and $6 \mathrm{~h}$ of aerobic phase. Since addition of toxicant drastically reduced the phosphate uptake during the first 90 min of aeration followed by subsequent uptake, it is recommended to perform the test with aerobic period duration of $6 \mathrm{~h}$ to calculate the $I C_{50}$ value. IC $C_{50}$ values increased substantially with extended aeration period-the values for $1.5,2.5,4$ and $6 \mathrm{~h}$ of aeration were $1.6,2.6,3.1$ and $3.9 \mathrm{mg} \mathrm{L}^{1}$, respectively. Furthermore, $100 \%$ of phosphorus uptake rate was inhibited under inhibitor concentration of $3 \mathrm{mg} \mathrm{L}^{-1}$ when calculations were made with values achieved after $1.5 \mathrm{~h}$ of aeration and under $6.5 \mathrm{mg} \mathrm{L}^{-1}$ when $6 \mathrm{~h}$ of aeration was applied. Shorter aeration period is feasible to show the effective concentration of inhibitor $\left(\mathrm{EC}_{50}\right)$, but longer aeration period is required for $\mathrm{IC}_{50}$ values. Longer application of hydraulic retention time in aerobic basin could diminish of the EBPR process inhibition.

Table 3 Validation parameters of developed method for estimating the impact of hazardous substances on activated sludge biological phosphorus removal process

\begin{tabular}{lll}
\hline Validation characteristic & Unit & Value \\
\hline Number of parallels & - & 7 \\
Average $\mathrm{IC}_{50}$ value & $\mathrm{mg} \mathrm{L}^{-1}$ & 3.9 \\
Standard deviation & $\mathrm{mg} \mathrm{L}^{-1}$ & 1 \\
$95.4 \%$ confidence level, $k=2$ & $\mathrm{mg} \mathrm{L}^{-1}$ & $2 \ldots 5.9$ \\
Relative standard deviation & $\%$ & 24.9 \\
\hline
\end{tabular}

\subsection{Reliability of the method}

Validation parameters were calculated in order to compare obtained results with other inhibition tests available for activated sludge treatment processes (Table 3). ISO 8192 gives average $\mathrm{IC}_{50}$ value of $9.3 \pm 3 \mathrm{mg} \mathrm{L}^{-1}$ with $95.4 \%$ confidence level values from 7.1 to $11.3 \mathrm{mg} \mathrm{L}^{-1}$. ISO 9509 gives average $\mathrm{IC} \mathrm{C}_{50}$ value of $5.6 \pm 3 \mathrm{mg} \mathrm{L}^{-1}$ for $3,5-\mathrm{DCP}$ with $95.4 \%$ confidence level values from 0.7 to $9.6 \mathrm{mg} \mathrm{L}^{-1}$. Additionally, denitrification inhibition test has been shown average $I C_{50}$ value of 5.5 with $95.4 \%$ confidence level values from $1.2 \ldots 9.8 \mathrm{mg} \mathrm{L}^{-1}[25]$. A high variation in activated sludge experiments is inevitable due to several methodical aspects: (1) activated sludge taken from WWTP during different seasons has different activity, (2) uncertainties from measurements, (3) changing the environment of inoculum when it is transported to laboratory (e.g., temperature and sludge washing). However, these methods are feasible to estimate the inhibition trends and to identify the origin of flows causing inhibition of activated sludge treatment processes.

\subsection{Impact of 3,5-dichlorophenol on different activated sludge treatment processes}

$3,5-D C P$ is a reference inhibitory compound which is used for estimating the reliability of different activated sludge tests. Impact of 3,5-DCP on activated sludge oxygen consumption, nitrification and denitrification processes was analyzed with the same activated sludge used in this study (Table 1, Fig. 6). All processes, except nitrification, are performed by heterotrophs. Although higher $\mathrm{IC}_{50}$ value was obtained for anaerobic phosphorus release test than oxygen uptake test, anaerobic phosphorus release was the least inhibited process up to $3,5-\mathrm{DCP}$ concentration of $5.9 \mathrm{mg} \mathrm{L}^{-1}$. Anaerobic phosphorus release was as sensitive as denitrification
Fig. 6 Inhibition curves of nitrification, denitrification, oxygen uptake, phosphate release and phosphate uptake processes under 3,5-dichlorophenol concentrations from 0 to $10 \mathrm{mg} \mathrm{L}^{-1}$

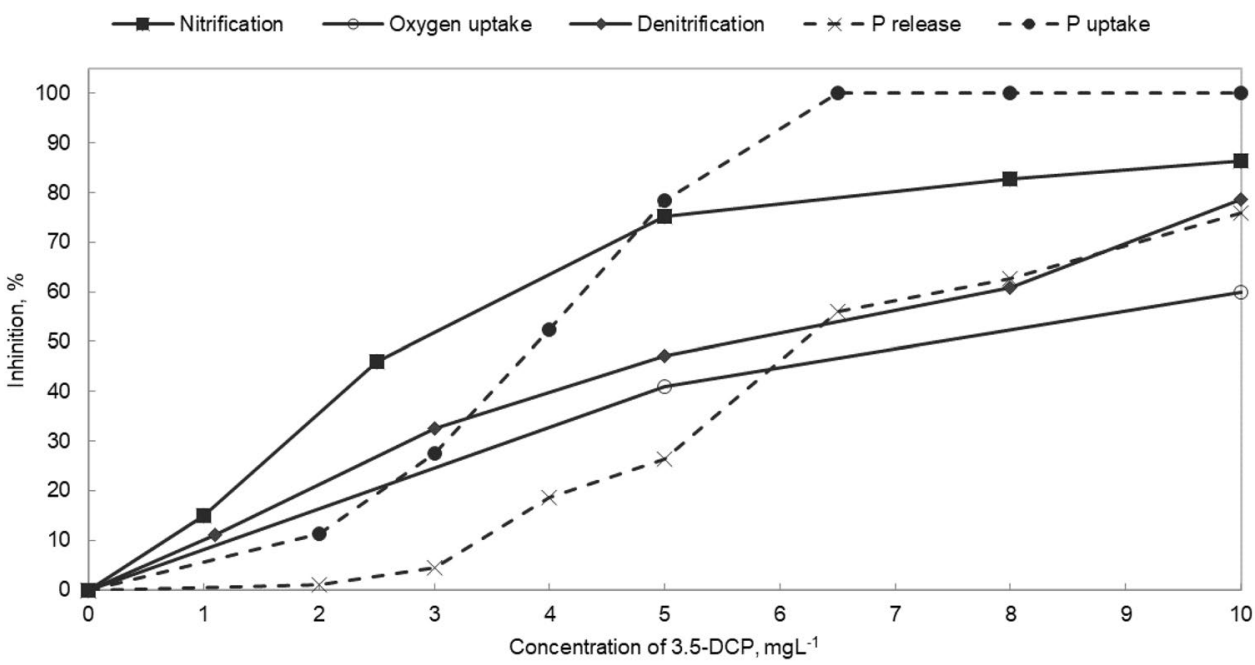


process starting from inhibitor concentrations of 6.5 $\mathrm{mg} \mathrm{L}^{-1}$. Aerobic phosphorus uptake had higher inhibition than anaerobic release process. Furthermore, aerobic phosphate uptake was the most sensitive activated sludge process at inhibitor concentration above 4.8 $\mathrm{mg} \mathrm{L}^{-1}$. Nitrification was the most sensitive process at lower inhibitor concentrations which coincides with the results reported by Inglezakis et al. [31]. Higher sensitivity of aerobic metabolism of PAOs has been explained by greater biomass growth and enzymatic activity under aerobic conditions [17]. Additionally, a cumulative inhibitory effect caused by inhibition of PHA synthesis in preceding anaerobic phase should be considered. It is advisable to estimate the impact of hazardous substance or wastewater on the EBPR process based on the reduction of phosphate uptake rate which considers the potential reduction in anaerobic PHA synthesis.

\section{Conclusions}

The enhanced biological phosphorus removal process is usually the first process in activated sludge treatment plant and therefore vulnerable to different process inhibitors. Although anaerobic phosphorus release was found to be the least inhibited process compared to other wastewater treatment processes, a cumulative process inhibition caused by inhibition of anaerobic PHA synthesis resulting in lower energy production should be considered. Furthermore, aerobic phosphorus uptake was found to be the most sensitive activated sludge process under 3,5-dichlorophenol concentration above $4.8 \mathrm{mg} \mathrm{L}^{-1}$. This method could be used for evaluation of EBPR inhibition caused by industrial wastewater or for measuring the inhibitory characteristics of any substance or mixture. The achieved validation parameters are in compliance with respective values given for other activated sludge processes.

Funding The authors would like to express their gratitude to the Estonian Ministry of Education and Research for the institutional research funding IUT20-16 and the Environmental Investment Centre for the project "Practical application of end of waste criteria for sewage sludge in Estonian water utilities" (code14616).

\section{Compliance with ethical standards}

Conflict of interest The authors declare that they have no conflict of interest.

\section{References}

1. Wang D, Yang G, Li X et al (2012) Inducing mechanism of biological phosphorus removal driven by the aerobic/extendedidle regime. Biotechnol Bioeng 109:2798-2807. https://doi. org/10.1002/bit.24543

2. Oehmen A, Lemos PC, Carvalho G et al (2007) Advances in enhanced biological phosphorus removal: from micro to macro scale. Water Res 41:2271-2300. https://doi.org/10.1016/j.watre s.2007.02.030

3. Oehmen A, Zeng RJ, Yuan Z, Keller J (2005) Anaerobic metabolism of propionate by polyphosphate-accumulating organisms in enhanced biological phosphorus removal systems. Biotechnol Bioeng 91:43-53. https://doi.org/10.1002/bit.20480

4. Saunders AM, Oehmen A, Blackall LL et al (2003) The effect of GAOs (glycogen accumulating organisms) on anaerobic carbon requirements in full-scale Australian EBPR (enhanced biological phosphorus removal) plants. Water Sci Technol 47:37-43. https ://doi.org/10.2166/wst.2003.0584

5. Katsou E, Alvarino T, Malamis S et al (2016) Effects of selected pharmaceuticals on nitrogen and phosphorus removal bioprocesses. Chem Eng J 295:509-517. https://doi.org/10.1016/j. cej.2016.01.012

6. Tsai YP, Chen HT (2011) Influence of sludge retention time on tolerance of copper toxicity for polyphosphate accumulating organisms linked to polyhydroxyalkanoates metabolism and phosphate removal. 102:11043-11047. https://doi. org/10.1016/j.biortech.2011.09.050

7. Chen Y, Liu C, Nie J et al (2014) Removal of COD and decolorizing from landfill leachate by Fenton's reagent advanced oxidation. Clean Technol Environ Policy 16:189-193. https://doi. org/10.1007/s10098-013-0627-1

8. Wang Y, Ren Z, Jiang F et al (2011) Effect of copper ion on the anaerobic and aerobic metabolism of phosphorus-accumulating organisms linked to intracellular storage compounds. J Hazard Mater 186:313-319. https://doi.org/10.1016/j.jhazm at.2010.11.007

9. Welles L, Lopez-Vazquez CM, Hooijmans CM et al (2014) Impact of salinity on the anaerobic metabolism of phosphate-accumulating organisms (PAO) and glycogen-accumulating organisms (GAO). Appl Microbiol Biotechnol 98:7609-7622. https://doi. org/10.1007/s00253-014-5778-4

10. Rubio-Rincón FJ, Lopez-Vazquez CM, Welles L et al (2017) Sulphide effects on the physiology of Candidatus Accumulibacter phosphatis type I. Appl Microbiol Biotechnol 101:1661-1672. https://doi.org/10.1007/s00253-016-7946-1

11. Zheng $X$, Sun $P$, Han J et al (2014) Inhibitory factors affecting the process of enhanced biological phosphorus removal (EBPR) a mini-review. Process Biochem 49:2207-2213. https://doi. org/10.1016/j.procbio.2014.10.008

12. Zhao J, Xin M, Zhang J et al (2020) Diclofenac inhibited the biological phosphorus removal: performance and mechanism. Chemosphere 243:125380. https://doi.org/10.1016/j.chemospher e.2019.125380

13. ISO-9509:2006 (2006) Water quality-Toxicity test for assessing the inhibition of nitrification of activated sludge 329 microorganisms

14. ISO-8192:1989 (1989) Water quality - method for assessing the inhibition of nitrification of activated sludge 331 microorganisms by chemicals and wastewaters

15. ISO-9888:1999 (1999) Water quality-evaluation of ultimate aerobic biodegradability of organic compounds in 333 aqueous medium — static test (Zahn-Wellens method)

16. Trapido M, Tenno T, Goi A et al (2017) Bio-recalcitrant pollutants removal from wastewater with combination of the Fenton 
treatment and biological oxidation. J Water Process Eng 16:277282. https://doi.org/10.1016/j.jwpe.2017.02.007

17. Wu G, Rodgers $M(2010)$ Inhibitory effect of copper on enhanced biological phosphorus removal. Water Sci Technol. https://doi. org/10.2166/wst.2010.431

18. Fernando EY, Jon S, Marta M et al (2019) Resolving the individual contribution of key microbial populations to enhanced biological phosphorus removal with Raman-FISH. ISME J. https://doi. org/10.1038/s41396-019-0399-7

19. APHA (1985) Standard methods for the examination of water and wastewater, 16th edn. American Water 343 Works Association Water Environment Federation, Washington

20. Oehmen A, Keller-Lehmann B, Zeng RJ et al (2005) Optimisation of poly- $\beta$-hydroxyalkanoate analysis using gas chromatography for enhanced biological phosphorus removal systems. J Chromatogr A 1070:131-136. https://doi.org/10.1016/j.chrom a.2005.02.020

21. Zhang $L$, Zheng $P, H e ~ Y$, Jin R (2009) Performance of sulfatedependent anaerobic ammonium oxidation. Sci China Ser B Chem 52:86-92. https://doi.org/10.1007/s11426-008-0161-x

22. Zeng W, Li B, Yang Y et al (2014) Impact of nitrite on aerobic phosphorus uptake by poly-phosphate accumulating organisms in enhanced biological phosphorus removal sludges. Bioprocess Biosyst Eng 37:277-287. https://doi.org/10.1007/s0044 9-013-0993-4

23. Zhou Y, Ganda L, Lim M et al (2012) Response of poly-phosphate accumulating organisms to free nitrous acid inhibition under anoxic and aerobic conditions. Bioresour Technol 116:340-347. https://doi.org/10.1016/j.biortech.2012.03.111

24. Rubio-Rincón FJ, Welles L, Lopez-Vazquez CM et al (2019) Effect of lactate on the microbial community and process performance of an EBPR system. Front Microbiol 10:1-11. https ://doi.org/10.3389/fmicb.2019.00125

25. Klein K, Tenno T (2019) Estimating the impact of inhibitory substances on activated sludge denitrification process. Water Pract Technol. https://doi.org/10.2166/wpt.2019.069

26. Arora PK, Bae H (2014) Bacterial degradation of chlorophenols and their derivatives. Microb Cell Fact 13:31. https://doi. org/10.1186/1475-2859-13-31

27. Tykesson $E$, Aspegren $H$, Henze $M$ et al (2002) Use of phosphorus release batch tests for modelling an EBPR pilot plant. Water Sci Technol 45:99-106

28. Seviour RJ, Mino T, Onuki M (2003) The microbiology of biological phosphorus removal in activated sludge systems. FEMS Microbiol Rev 27:99-127. https://doi.org/10.1016/S0168 -6445(03)00021-4

29. Lin H, Gan J, Rajendran A, Reis CER, Hu B (2015) Phosphorus removal and recovery from digestate after biogas production. In: Biofuels - status and perspective. Intech Open, pp 517-546. https://doi.org/10.5772/60474

30. Klein K, Kattel E, Goi A et al (2017) Combined treatment of pyrogenic wastewater from oil shale retorting. Oil Shale 34:82-96. https://doi.org/10.3176/oil.2017.1.06

31. Inglezakis VJ, Malamis S, Omirkhan A et al (2017) Investigating the inhibitory effect of cyanide, phenol and 4-nitrophenol on the activated sludge process employed for the treatment of petroleum wastewater. J Environ Manag 203:825-830. https:// doi.org/10.1016/j.jenvman.2016.08.066

Publisher's Note Springer Nature remains neutral with regard to jurisdictional claims in published maps and institutional affiliations. 